\title{
UM OLHAR SEMÂNTICO SOBRE O CONTEÚDO DOS LIVROS DIDÁTICOS DO ENSINO MÉDIO
}

\section{A SEMANTIC GLANCE AT THE CONTENTS OF THE TEXTBOOKS OF HIGH SCHOOL}

\author{
Ednaldo Tartaglia Santos \\ Doutorando em Letras da Universidade Estadual de Maringá \\ Mestre em Letras pela Universidade Federal de Rondônia \\ Professor da Universidade Federal do Amapá \\ E-mail: dinaldots@hotmail.com \\ Maria do S. D. Loura Jorrin \\ Doutora em Educação Escolar pela Universidade Estadual de São Paulo \\ Professora da Universidade Federal de Rondônia \\ E-mail: diasocorromaria@gmail.com
}

\section{RESUMO}

O presente trabalho tem por objetivo verificar como ou se os estudos semânticos estão sendo inseridos nos materiais didáticos do ensino médio propostos para as escolas públicas brasileiras. $\mathrm{O}$ nosso corpus de estudo foi o livro Português: volume único (MAIA, 2005) e as coleções Língua Portuguesa: Linguagem e Interação (FARACO et al., 2010) e Português Linguagens (CEREJA; MAGALHÃES, 2010), todos distribuídos pelo Ministério da Educação (MEC). Com a análise dos materiais, observamos que alguns autores têm resistência em utilizar e incluir em suas obras os estudos dos significados ou a palavra Semântica, em contrapartida, encontramos autores que tiveram tal preocupação na organização dos materiais didáticos.

Palavras-chave: Língua portuguesa. Semântica. Livro didático. Educação.

\begin{abstract}
This study aims to determine how or if the semantic studies are being inserted into the teaching materials of high school proposed for the Brazilian public schools. Our corpus was the Portuguese book: single volume (MAIA, 2005) and the collections Portuguese Language: Language and Interaction (FARACO et al., 2010) and Portuguese: languages (CEREJA; MAGALHÃES, 2010), all distributed by the Ministry of Education - MEC. With the analysis of the materials, we observed that some authors have resistance to use and include in his works the study of meaning or semantic word, however, we find authors that had such concern in the organization of teaching materials.
\end{abstract}

Keywords: Portuguese Language. Semantics. Textbook. Education. 


\section{INTRODUÇÃO}

Este artigo é o resultando de uma pesquisa realizada, no ano de 2014, em livros didáticos do ensino médio. Nossa pergunta de pesquisa foi como ou se a Semântica está sendo inserida nos materiais didáticos do ensino médio destinados ao ensino de língua portuguesa.

Analisamos sete livros distribuídos pelo Programa Nacional do Livro Didático do Ministério da Educação (PNLD/MEC) e pelo Programa Nacional do Livro Didático para o ensino médio, também pelo Ministério da Educação (PNLEM/MEC): Português: volume único, do autor João Domingues Maia, destinado ao ensino médio pelo PNLEM para o período de 2009 a 2010; a Coleção Língua portuguesa: linguagem e interação, dos autores Carlos Emílio Faraco, Francisco Marto de Moura e José Hamilton Maruxo Júnior, proposto pelo PNLD para os anos de 2012 a 2014, que está organizado em três volumes, cada um destinado a uma série do ensino médio; e, por fim, a Coleção Português linguagens, de autoria de William Roberto Cereja e Thereza Cachar Magalhães, distribuído pelo PNLD para atender no período de 2012 a 2014, também dividida em três volumes propostos para as três últimas séries da educação básica.

Fizemos um levantamento histórico a respeito de Semântica, da dificuldade de sua aceitação pela Linguística, além de uma investigação sobre várias concepções encontradas para essa ciência. Expomos, em síntese, que a Semântica não se constitui como campo homogêneo, mas sim em várias correntes que se debruçam nos estudos dos significados.

\section{A LINGUÍSTICA E O ESTUDO DO SIGNIFICADO COMO CIÊNCIA}

No mundo científico, teorias e modelos distintos se sucedem no tempo e, muitas vezes, coexistem em um mesmo período. Assim sendo, acreditamos que não seja diferente em se tratando de Semântica. De tal modo, nesse item, veremos algumas discussões a respeito da Linguística e de sua subdivisão, a Semântica.

Não podemos dar início a nossa abordagem Semântica sem fazer menção ao estruturalismo, especialmente, à figura do suíço Ferdinand Saussure e seu Curso de Linguística Geral. Saussure propõe, no Curso, o conceito de signo linguístico: significante e significado. Ele salienta que o "signo linguístico une não uma coisa e uma palavra, mas um conceito e uma imagem acústica" (SAUSSURE, 2006, p.80).

A partir dessa concepção, temos a noção de sistema linguístico, ou seja, Saussure define a língua como um sistema de signos. Ele insiste em caracterizar o signo como não material, daí a ideia de imagem acústica. Saussure propôs “conservar o termo signo para designar o total, e a 
substituir conceito e imagem acústica respectivamente por significado e significante" (id. ibid., p.81). Essas poucas explanações sobre seu trabalho servem para mencionar que, com base no desenvolvimento do conceito linguístico saussuriano, estudiosos se preocuparam com os estudos dos significados e contribuíram para a consolidação da Semântica como ciência.

Alguns estudiosos apontam a resistência dos linguistas em considerar a Semântica como parte da Linguística, como salienta Lyons: "há não muito tempo numerosos linguistas mantinham o ponto de vista de que a Semântica não era um ramo de sua ciência; que a Linguística deveria restringir-se ao estudo da 'forma' na linguagem." (LYONS, 1976, p. 23). Ele ainda afirma que, nos últimos anos, houve um notável interesse em estudar as teorias Semânticas.

\begin{abstract}
A mesma incoerência se verifica com respeito ao termo Gramática. Seu sentido tradicional (na realidade, o sentido em que se fala de "gramática tradicional") era bastante amplo. Em tempos recentes, tendeu a ser mais restrito: (1) a incluir a Morfologia e a Sintaxe, mas a excluir a Fonologia e a Semântica; ou (2) a incluir a Fonologia, de par com a Morfologia e a Sintaxe, mas a excluir a Semântica. Ainda mais recentemente, o termo "Gramática" voltou a ser empregado no sentido mais amplo que inclui também a Semântica (LYONS, 1976, p. 23).
\end{abstract}

Apreendemos, na citação acima, que historicamente havia uma resistência em não somente aceitar a Semântica como parte da Linguística, mas também de inseri-la como parte da "gramática". Porém, ela, a Semântica, vem se consolidando e ocupando seu espaço.

Sobre uma teoria Semântica, Bierwisch (1976) aponta três elementos essenciais:

em resumo, uma teoria Semântica deve: (a) fazer referência, de modo preciso, à estrutura sintática; (b) representar sistematicamente o significado das palavras isoladas (ou, mais genericamente, dos elementos léxicos, que incluem também frases lexicalizadas como idiotismo, compostos isolados, etc.); (c) mostrar como interagem a estrutura dos significados das palavras e as relações sintáticas para construir a interpretação de orações. Finalmente, deve mostrar como tais interpretações relacionam-se com as coisas de que se fala (BIERWISCH, 1976, p. 163).

Assim, de acordo com o autor, há uma ligação forte com a sintaxe, com o léxico e com a estrutura dos significados na formulação de um campo de estudo semântico. Nesse sentido, existem várias vertentes teóricas da Semântica, algumas se inter-relacionam buscando subsídios em outras correntes do campo semântico. Discorreremos sobre algumas mais adiante.

O que apresentamos acima foi uma explanação extremamente panorâmica sobre a Linguística e a Semântica para melhor compreensão do nosso objeto de estudo. Vimos que a Semântica não era vista com bons olhos por alguns linguistas, mas ela vem se solidificando. Assim, faz-se necessário compreender que não há uma corrente teórica aceita por todos os estudiosos do significado. Desse modo, com a dificuldade de se estabelecer como ciência e 
também com a dificuldade de inserção no campo linguístico, nossa preocupação é verificar, na atualidade, como ou se a Semântica está sendo inserida no ensino de língua portuguesa, nesse caso, especialmente, no ensino médio da rede pública.

\section{ABORDAGENS SEMÂNTICAS}

Neste item, veremos como a Semântica vem sendo conceituada. Para isso, apontaremos, a seguir, um rol de concepções que linguistas, lexicógrafos, gramáticos e semanticistas apontam sobre a Semântica. Encontramos em Ferreira (2010, p. 691) a seguinte definição: a Semântica é “o estudo das mudanças ou transladações sofridas, no tempo e no espaço, pela significação das palavras". Sacconi (2011, p. 512) conceitua a Semântica como "o estudo da significação das palavras e das suas mudanças de significação, através do tempo ou em determinada época. Assim, a Semântica pode ser sincrônica e diacrônica". Para Cereja e Magalhães (1999, p. 384), a "Semântica é a parte da gramática que estuda os aspectos relacionados ao sentido de palavras e enunciados". Cegalla (2005, p. 308) sucintamente afirma que a "Semântica trata da significação das palavras".

A Semântica, para Cançado (2005, p. 16), “é o estudo do significado das palavras e das sentenças". Borba (2008, p. 226) salienta que "O ramo da semiótica que se ocupa da significação ou dos sentidos veiculados pela linguagem chama-se Semântica”. Esse último autor adverte que os linguistas que almejam ser semanticistas precisam "limitar o alcance do termo Semântica ao estudo dos sistemas de noções vigentes nas línguas, isto é, ao enfoque da maneira como as noções, individuais ou não, se combinam em enunciados".

De acordo com Ferrarezi Jr e Basso (2013, p. 13), “o estudo do significado, em sua dimensão mais ampla (Semiótica) e em sua dimensão Linguística (Semântica), é, talvez, uma das mais antigas buscas do espírito humano". Os autores afirmam que essa "empreitada se confunde com nossa busca incessante por significado para tudo o que vemos, sentimos, enfim, experienciamos em nossa vivência diária”.

Ilari e Geraldi (2006, p. 6) estendem-se na conceituação e argumentam que "a Semântica é um domínio de investigação de limites movediços”. Eles apontam que semanticistas de distintas escolas empregam "conceitos e jargões sem medida comum, explorando em suas análises fenômenos cujas relações não são sempre claras". Para os autores "a Semântica aparece, em suma, não como um corpo de doutrina, mas como o terreno em que se debatem problemas cujas conexões não são sempre óbvias". 
Em sentido consensual e genérico, a Semântica é a área da Linguística que estuda os significados. Porém, os estudos semânticos não se resumem a essa campo de pesquisa, pois há várias correntes que se preocupam com o estudo dos significados. Segundo Müller e Viotti (2008, p. 137), precisamos compreender o que é o significado, e essa não é uma tarefa fácil porque os semanticistas têm diferentes visões a respeito do que seja o significado e a significação.

Contudo, podemos dizer que há várias dimensões de pesquisas para se estudar em Semântica como, por exemplo: o caminho para se chegar à condição de verdade de uma sentença (Semântica Formal); o processo de utilização de determinados sistemas conceituais para a transmissão e recepção de mensagens (Semântica Cognitiva); a formação e atribuição dos sentidos a partir de língua e cultura (Semântica Cultural); o processamento dos sentidos adequados ou não na relação homem e máquina (Semântica Computacional); o processo de compreensão de como aprender a produzir sentenças ou palavras que tenham certo sentido (Semântica e Psicologia Experimental); o estudo dos significados das palavras e sua relação com outros níveis linguísticos (Semântica Lexical); e várias outras doutrinas semânticas que não vamos expor aqui (CANÇADO, 2005; FERRAREZI JR; BASSO, 2013).

Possivelmente essas correntes não são totalmente incompatíveis, pois o significado possui realmente diversos ângulos. Assim, cada corrente teórica da Semântica se ocupa de pesquisar determinado(s) ângulo(s). O que as várias teorias semânticas fazem é recortar o objeto de estudo de formas diferentes, dando ênfase ao estudo de alguns aspectos relacionados à análise do significado. Por conseguinte, essas teorias vão, de alguma, forma dialogar entre si. Müller e Viotti (2008, p. 138) asseveram que "nenhuma teoria científica escapa a essa limitação, na medida em que todas elas precisam, necessariamente, recortar seu objeto de estudo".

Contudo, podemos compreender que há, de certa forma, uma complexidade de caminhos proporcionados pelas correntes semânticas. Como já mencionamos, nosso objetivo não é fazer um levantamento dessas correntes teóricas, mas sim fazer uma sondagem a respeito dos estudos semânticos em alguns materiais didáticos destinados ao ensino de língua portuguesa do ensino médio de escolas públicas.

\section{UM OLHAR SEMÂNTICO SOBRE OS LIVROS DIDÁTICOS DO ENSINO MÉDIO}

Assim como explicitamos na introdução, selecionamos livros e coleções de livros didáticos destinados ao ensino de língua portuguesa no ensino médio das escolas públicas. 
Verificamos se os autores desses livros utilizam alguma metodologia que contemple a inserção e o diálogo com estudos semânticos. A seguir apresentaremos uma análise de cada obra e apontaremos algumas considerações.

\subsection{PORTUGUÊS: VOLUME ÚNICO}

O livro Português: volume único, de João Domingues Maia, foi organizado para atender as três séries do ensino médio. Ele possui 47 unidades de estudos. Em uma primeira análise, no índice, não encontramos nenhuma unidade destinada especificamente à Semântica. Apontaremos algumas anotações a respeito dessa obra.

Na unidade 2, denominada Comunicação e expressão, temos um campo com o mesmo nome que, de alguma forma, trabalha a Semântica. Temos uma reflexão sobre o emprego das palavras num período. Vejamos o fragmento do texto $O$ gari de Arlete Nogueira da Cruz expresso na Figura 1:

COMUNICACAO

\section{E EXPRESSAO}

Miguel aproximourse es encontrando entre eles um velho amigo, contou-the o set infortuniala dizendo-se convidado mas barrado pela folto de um terno.

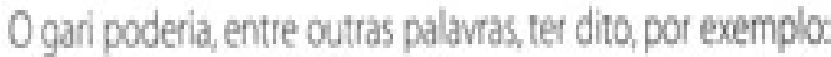

\section{- Que decepclol Fuil barrado porque náo estou de terno e gravata...}

\section{Figura 1: Fragmento de texto}

Fonte: Maia. Português: Volume único. 2005, p. 21.

O autor salienta que o gari poderia ter usado outras palavras como, por exemplo: “- Que decepção! Fui barrado porque não estou de terno e gravata...” (MAIA, 2005, p. 21). De certa forma, ao trabalhar questões voltadas para relação de significados entre sentenças, trabalha-se a sinonímia, especificamente, nesse caso, a paráfrase, pois, de acordo com Cançado (2005, p.42), a relação de sinonímia entre sentenças é chamada de paráfrase. Contudo, Maia aborda somente a comunicação na vertente emissão e recepção de informações entre os interlocutores. É relevante ressaltar que essa era a proposta do quadro de estudo.

Observamos, ainda na unidade 2, uma abordagem sobre signo linguístico trabalhando as questões: significante e significado.

Vejamos as atividades selecionadas na Figura 2: 
4. O gesto de Asterix, considerado como um signo, pode ser analisado como:

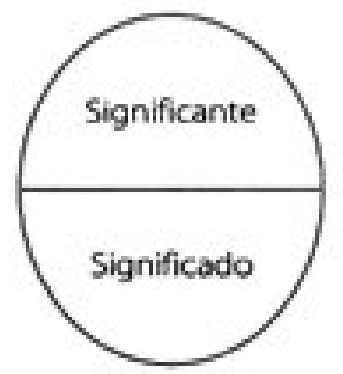

a) Descreva o significante.

b) Analise o significado.

5. Em relaçăo ao segundo quadrinho, responda:

a) Qual o significado universal do gesto de Asterix?

b) Quais os códigos usados por Asterix?

c) O que podemos deduzir do comportamento de Detritus?

6. Um mesmo significante pode ter vários significados, dependendo do contexto em que se encontre. De o significado da palavra quadro nas seguintes oraçœes:

a) O quadro foi furtado do Museu de Belas-Artes.

b) A aluna apagou o quodro ao termino da aula.

c) O ministro traçou um quadro da situaçăo politica.

d) O quadro de funcionários desta empresa é bem grande.

e) O diretor divulgou o quadro de alunos aprovados.
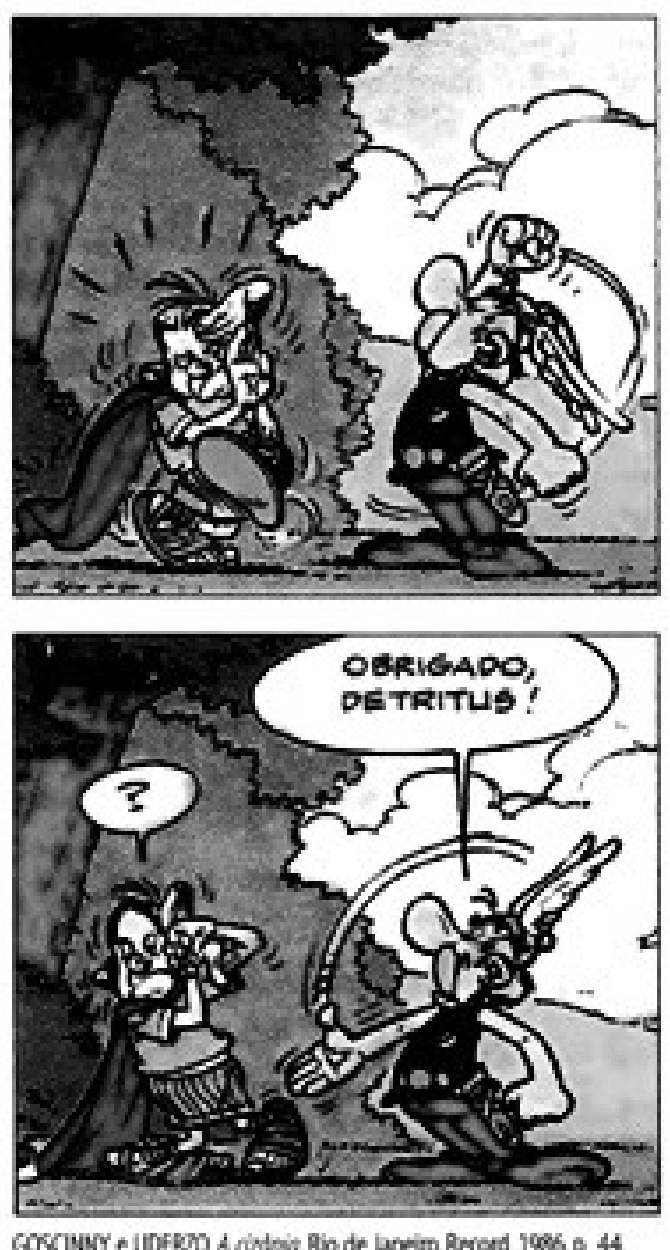

Figura 2: Fragmento de atividades

Fonte: Maia. Português: Volume único. 2005, p. 25.

$\mathrm{Na}$ Figura 2, temos questões relacionadas ao signo linguístico (Atividade 4). Já, na atividade 5, temos uma proposta que aborda a dedução de um significado universal, logo temos a possibilidade de trabalhar a pressuposição relacionada ao conhecimento prévio ou extralinguístico que as pessoas têm em comum (CANÇADO, 2005, p. 25).

A atividade 6, em sua abordagem, remete, indiretamente, à polissemia. A polissemia lida com os vários sentidos para uma mesma palavra, ela ocorre quando os possíveis sentidos da palavra ambígua têm alguma relação entre si (CANÇADO, 2005, p. 63-64; ILARI; GERALDI, 2006, p. 57-8). Nesse sentido, Cançado (2005, p. 64) acrescenta que palavras "polissêmicas serão listadas como tendo uma mesma entrada lexical, com algumas características diferentes". Assim, observamos, nas três atividades da Figura 2, um estudo ligado às vertentes semânticas, porém, em nenhum momento, nesse capítulo, encontramos os conceitos de pressuposição e polissemia. 
Na unidade 4, denominada As palavras no texto (II), temos a maior referência aos estudos semânticos. No campo $O$ sentido das palavras, o autor trabalha os quesitos: denotação e conotação. Na Figura 03, temos algumas atividades que contemplam esses estudos, analisando o sentido que as palavras proporcionam.

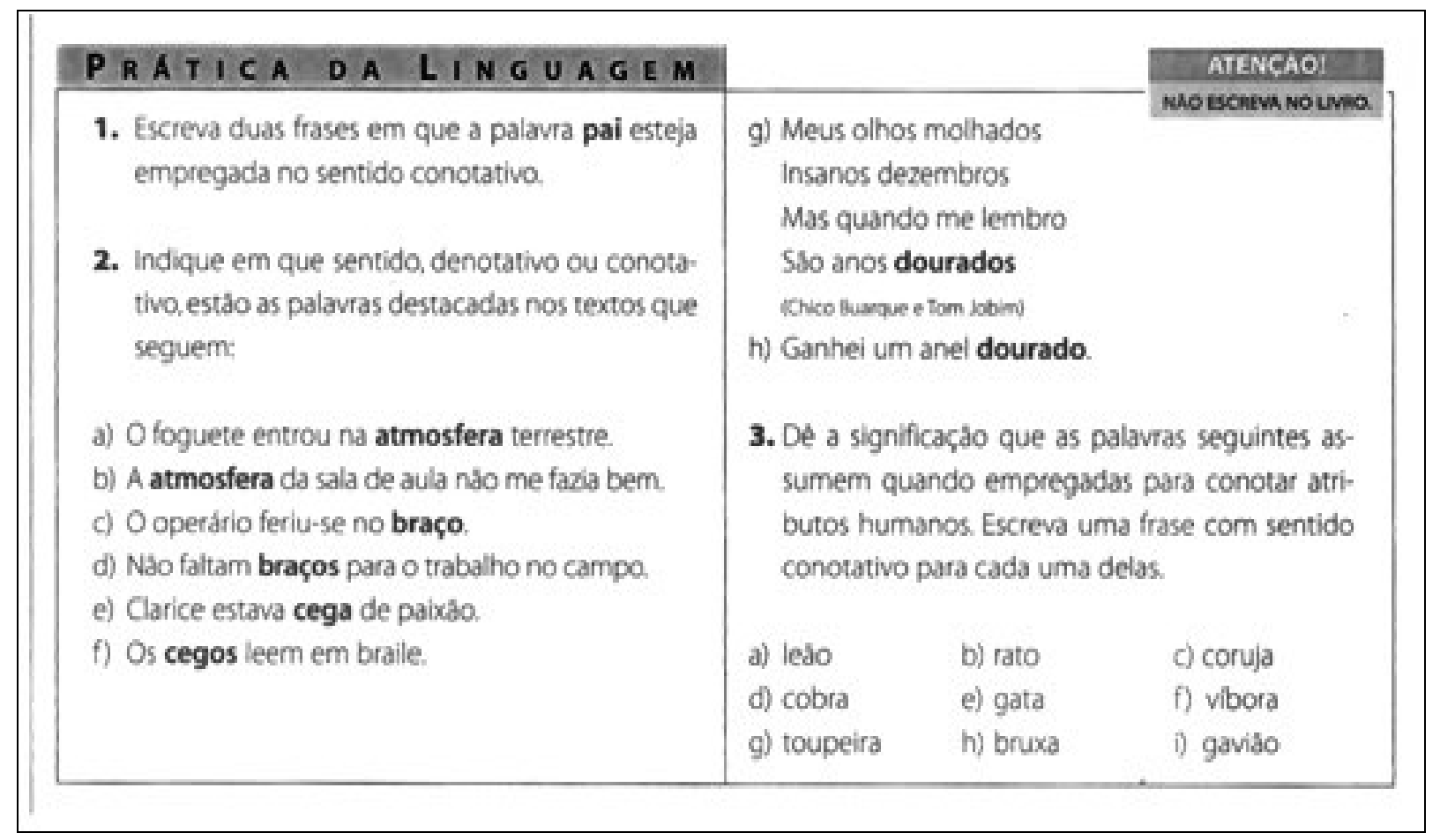

\section{Figura 3: Fragmento de atividades}

Fonte: Maia. Português: Volume único. 2005, p. 42

Nas atividades supracitadas, temos, é claro, o estudo sobre o conteúdo proposto, conotação e denotação, mas há novamente recursos para o autor ampliar a abordagem de conteúdos semânticos como a polissemia e a paródia, a exemplo do que fez em relação à conotação e denotação. Porém, não podemos esquecer que o autor manteve uma coerência em relação ao conteúdo trabalhado e a sua aplicação.

Ainda na unidade 4, o autor utiliza a tira (Figura 4) para fazer uma reflexão sobre homônimos e parônimos. Ele traz a seguinte definição para homônimos "quando duas palavras têm significados diferentes e grafia idêntica" (MAIA, 2005, p 43). Posteriormente, temos um esboço sobre os tipos de homônimos e uma definição para parônimos: "são vocábulos semelhantes na escrita e na pronúncia" (id.ibid., p. 43). Em seguida, temos duas atividades para exercitar o emprego das parônimas e homônimas. Após as atividades mencionadas, o conteúdo é direcionado para a produção de texto. 


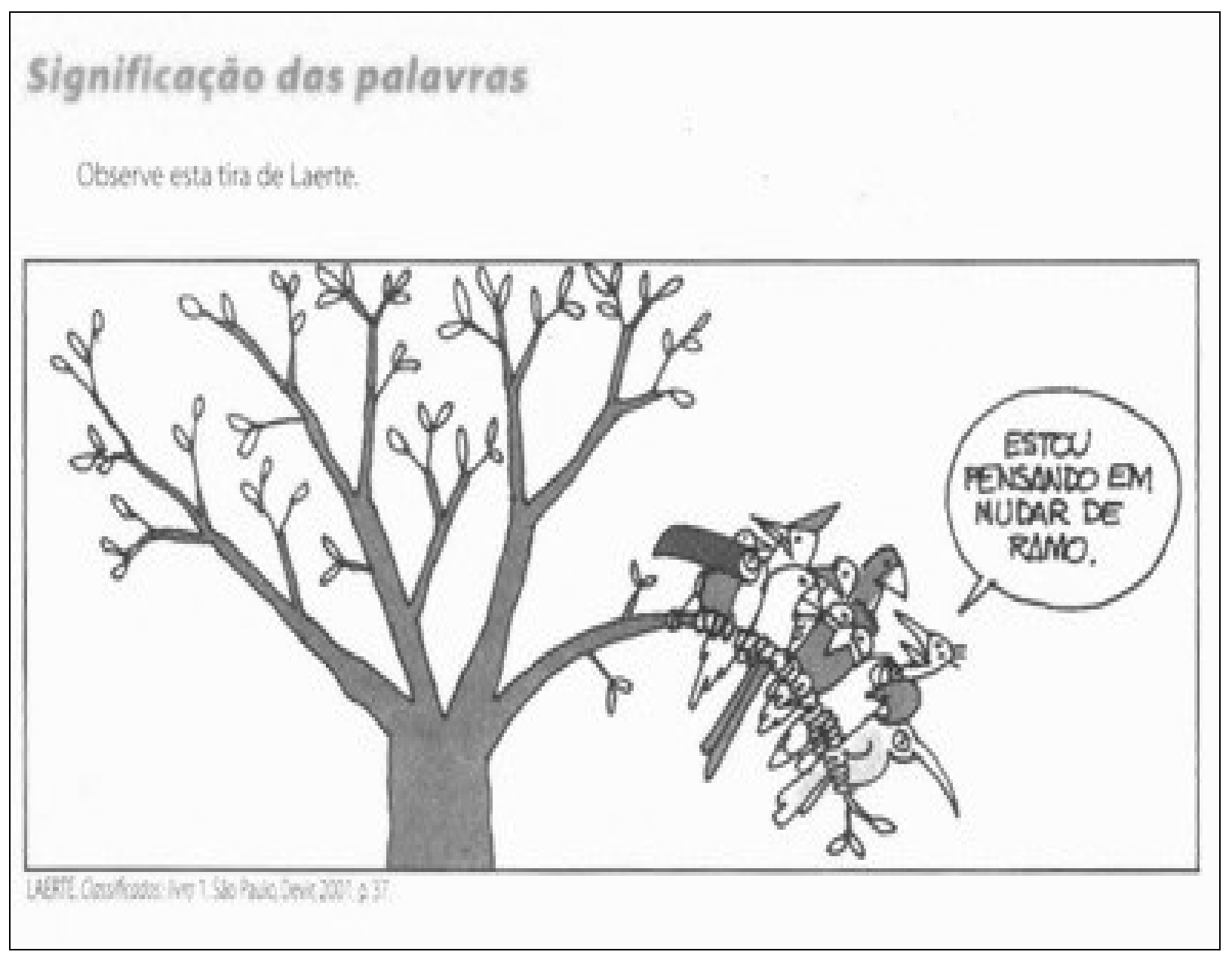

Figura 4: Fragmento de tira

Fonte: Maia. Português: Volume único. 2005, p. 42

Ao longo das outras unidades encontramos peças publicitárias e propagadas que utilizam do jogo de significados para trabalharem, de certa forma, com o sentido das palavras. Observamos textos, frases, tiras, peças publicitárias e propagandas que possibilitariam, pela sua riqueza de sentido, estudar a semântica com mais ênfase, atribuindo ao estudo semântico o espaço que é necessário, mas constatamos que esse espaço não é privilegiado de maneira adequada. Ele deu ênfase à produção textual, à literatura, aos movimentos literários, às questões de sintaxe e às de morfologia. Porém, esses não são nossos prismas de análise.

Assim, no livro Português: volume único, verificamos que há carência de estudos diretamente semânticos, ou seja, a análise semântica não parece ser uma preocupação. Mas não podemos dizer que o autor não trabalhou a semântica, pois observamos, em suas atividades, abordagens reflexivas de alguns campos da semântica em meio à literatura, produção e interpretação de textos. É importante salientar que o autor se preocupou em organizar, na maioria dos textos, um glossário para levar os alunos a uma maior compreensão das palavras nos textos. 


\subsection{LÍNGUA PORTUGUESA: LINGUAGENS E INTERAÇÃO}

Analisamos também a Coleção Língua Portuguesa: Linguagem e Interação dos autores Carlos Emílio Faraco, Francisco Marto de Moura e José Hamilton Maruxo Júnior. A Coleção está dividida em três volumes, cada um destinado a uma série do ensino médio. Os volumes são divididos em unidades e, por sua vez, subdivididos em capítulos.

Na Coleção Língua Portuguesa: Linguagem e Interação, observamos que há uma preocupação dos autores em orientar os alunos a uma melhor compreensão da leitura, já que eles inseriram, em alguns textos, glossários, o que contribui para a compreensão e interpretação do leitor.

A coleção traz alguns campos que contemplam de alguma forma o sentido das palavras, como, por exemplo, os campos denominados: Para entender o texto, As palavras no contexto, Língua - análise e reflexão. Esses campos possuem atividades de interpretação textual, com abordagens e conceitos gramaticais que se inter-relacionam com os estudos dos significados.

No volume 1, no campo As palavras no contexto, temos uma abordagem a respeito da troca de palavras para não repeti-las no texto, como barbeiro por a tesoura e a navalha, ou seja, é possível estabelecer uma relação de significação entre as expressões (Figura 5).

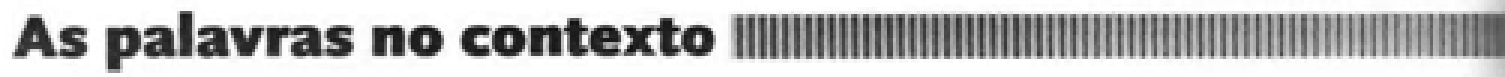

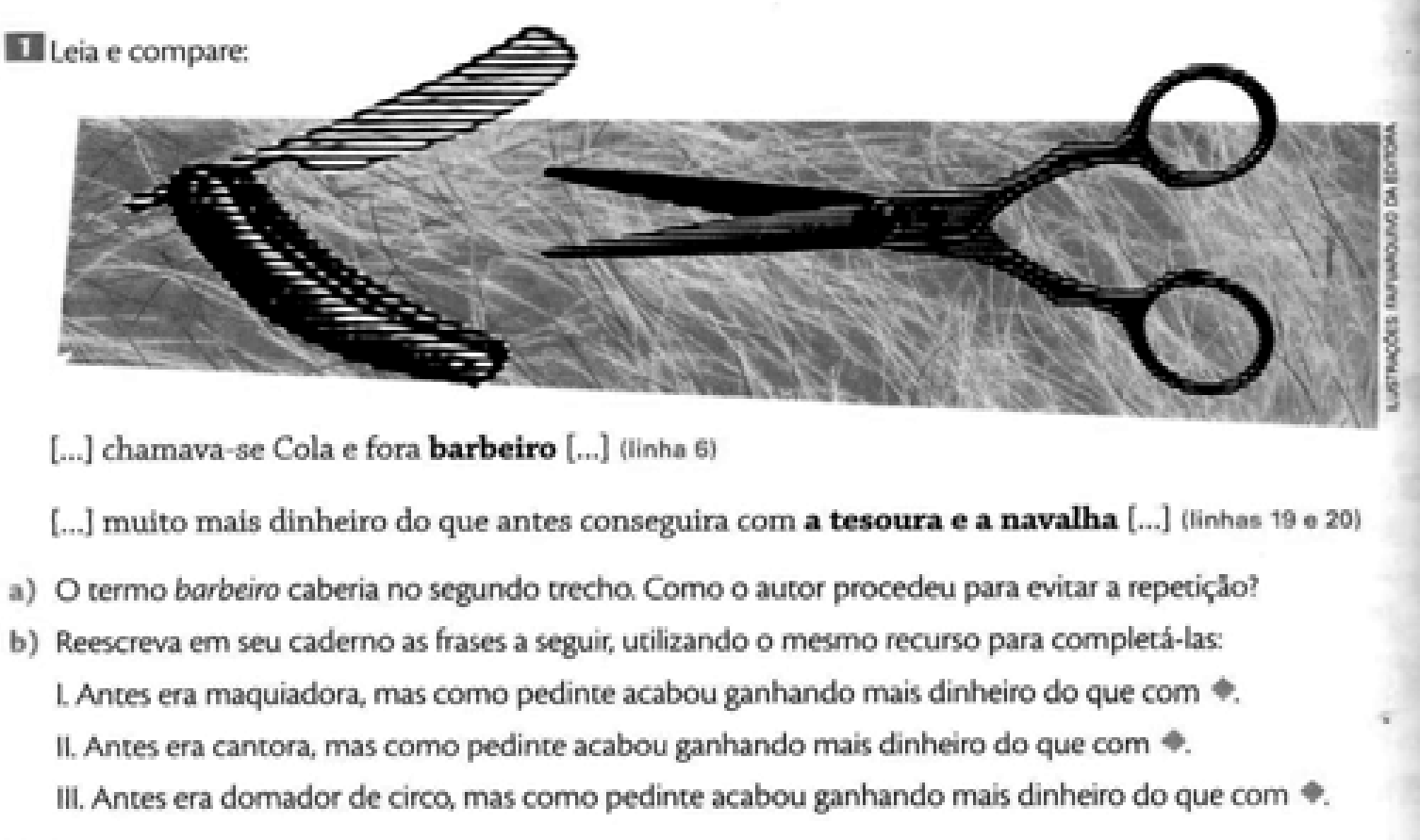

\section{Figura 5: Fragmento de atividades}

Fonte: Faraco et al. Vol. 1, 2010a, p. 54 
Na Figura 5, o falante da expressão "chamava-se Cola e fora barbeiro" aceita como condição de verdade a troca da palavra barbeiro na segunda expressão para a tesoura e a navalha. Nesse caso, temos uma relação de acarretamento que a Semântica moderna denomina, segundo Ilari e Geraldi (2006, p. 51), de hiponímia.

A relação hiponímia é aquela que intercorre entre expressões com sentido mais específico e expressões genéricas, por exemplo, entre geladeira, liquidificador, batedeira de bolos, ferro elétrico etc. e eletrodoméstico; é a relação que intercorre entre pardal e passarinho, e que verbalizamos dizendo que todo pardal é um passarinho, mas nem todo passarinho é um pardal (ILARI E GERALDI, 2006, p. 52).

Os autores acrescentam que "a relação de hiponímia estrutura o vocabulário da língua em grandes quadros classificatórios, mais ou menos harmoniosos” (ILARI E GERALDI, 2006, p. 52). Assim, a atividade da Figura 5 trabalha indiretamente a hiponímia como recurso para evitar a repetição de palavras nos textos, mas o conceito de hiponímia e sua relação com as palavras não são apresentados pelos autores.

No capítulo 7, ainda do volume 1, no campo Língua - análise e reflexão, temos o item $O$ léxico e os sentidos das palavras, no qual os autores abordam mais detalhadamente alguns conceitos semânticos, como a sinonímia, a antonímia, o hipônimo e hiperonímia. As conceituações são apresentadas através de comentários relacionando os textos estudados no capítulo com alguns exemplos para melhor assimilação das definições. Contudo, observamos, nesses enfoques a respeito do léxico e do sentido das palavras, uma abordagem com poucos exemplos e uma carência em atividades para praticar o emprego e a análise dessas concepções semânticas.

Direcionando nossa análise para o volume 2, no campo As palavras no contexto, temos atividades relacionadas ao fragmento do texto Dois irmãos de Milton Hatoum. Os autores trabalham o sentido de alguns verbos e substantivos. Vejamos:

As atividades da Figura 6 exploram o sentido não literal das palavras empregadas em fragmentos do texto e também de palavras regionais. Os autores aproveitam a utilização dessas palavras para trabalhar figuras de linguagem.

Passamos para o volume 3 da coleção Língua Portuguesa: linguagem e interação. Analisando o sumário desse volume, vimos que não há nenhum capítulo ou campo destinado às abordagens semânticas. No entanto, verificamos algumas investidas em atividades que contemplam, de forma indireta, os estudos das significações, que descreveremos a seguir. 


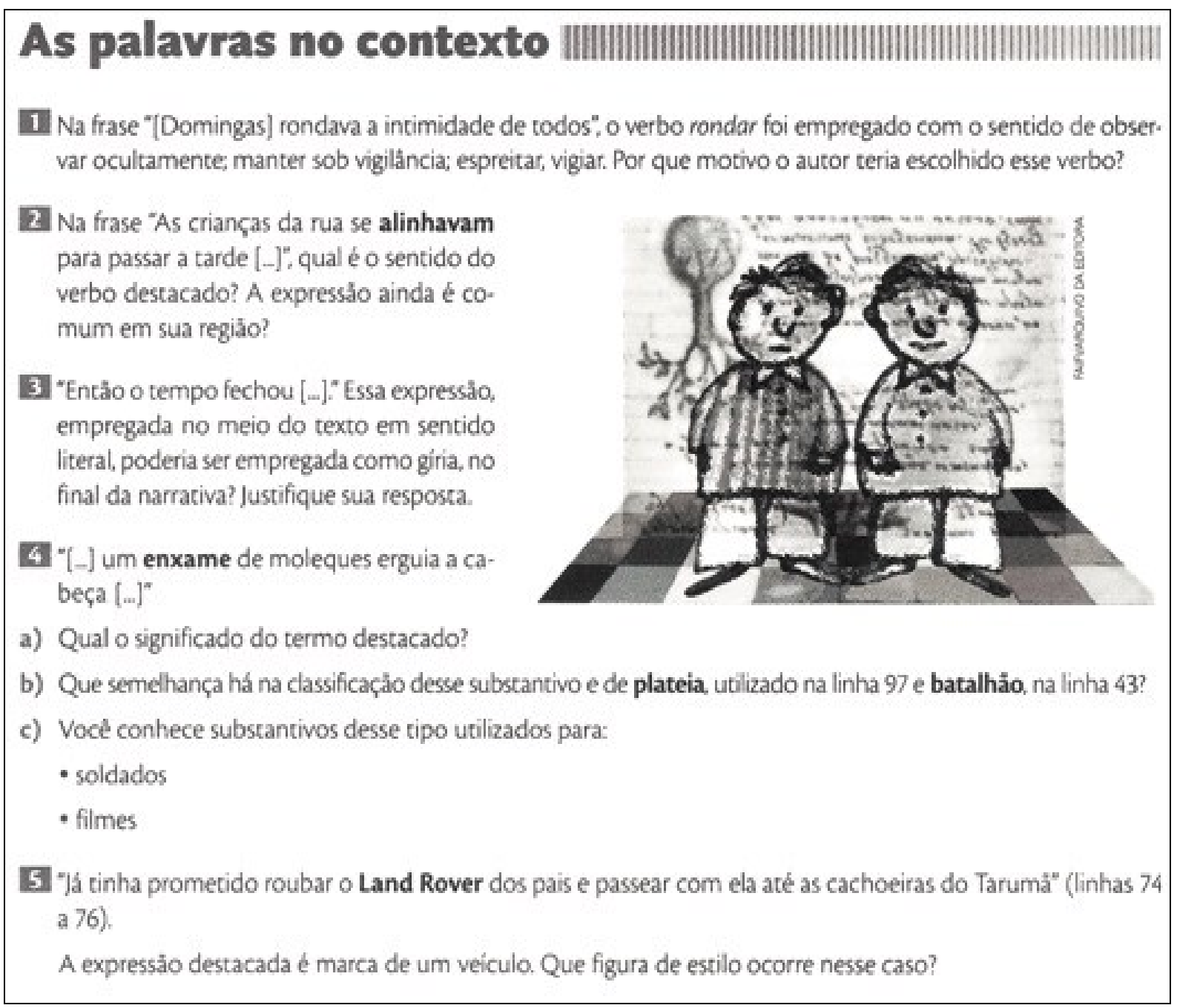

\section{Figura 6: Fragmento de atividades}

Fonte: Faraco et al. Vol. 2, 2010b, p. 54.

No capítulo 3, volume 3, temos, no campo Para compreender o texto, uma atividade referente ao texto A língua absolvida de Elias Canetti. A atividade aborda o sentido da palavra. Em meio a questões de interpretação textual, o texto (Figura 7) conduz o aluno a uma reflexão a respeito do sentido figurado que as palavras podem apresentar. Os autores poderiam ter trabalhado o significado real e o significado no contexto, inclusive, ter relacionado a atividade ao campo semântico dos sinônimos. Porém, há somente esta abordagem do sentido no fragmento do texto.

\footnotetext{
Muitas vezes lhe pedi essa história, e ele gostava de contá-la. Assim, os lobos foram os primeiros animais selvagens que povoaram a minha fantasia. $O$ terror que eles me infundiam era alimentado pelos contos que ouvia das camponesas búlgaras. [...]
}

Em seu caderno, explique o trecho destacado.

\section{Figura 7: Fragmento de texto}

Fonte: Faraco et al. Vol. 3, 2010c, p. 69. 
Observamos, na Coleção Língua Portuguesa: Linguagem e interação, que há uma preocupação em estudar os sentidos proporcionados pelas palavras e vimos que, no volume 1, há abordagens que contemplam alguns segmentos da Semântica. Vimos também que os autores se preocuparam em inserir, nas atividades de interpretação textual dos três volumes, questões reflexivas sobre o uso de certas palavras nas orações e em alguns fragmentos de texto.

\subsection{PORTUGUÊS LINGUAGENS}

Analisamos também a coleção Português linguagens de autoria de William Roberto Cereja e Thereza Cochar Magalhães. A coleção também está dividida em três volumes que, por sua vez, destinam-se as três séries do ensino médio. Eles estão divididos em unidades e em capítulos.

Nessa coleção há um capítulo destinado ao estudo semântico denominado Introdução à Semântica e vários capítulos dos volumes trazem um tópico denominado Semântica e discurso. Apontaremos a seguir algumas dessas abordagens.

Leila a tira a seguir e responda ds questibes 1 e 2.

\section{NiCOLAU. Lues Lima}
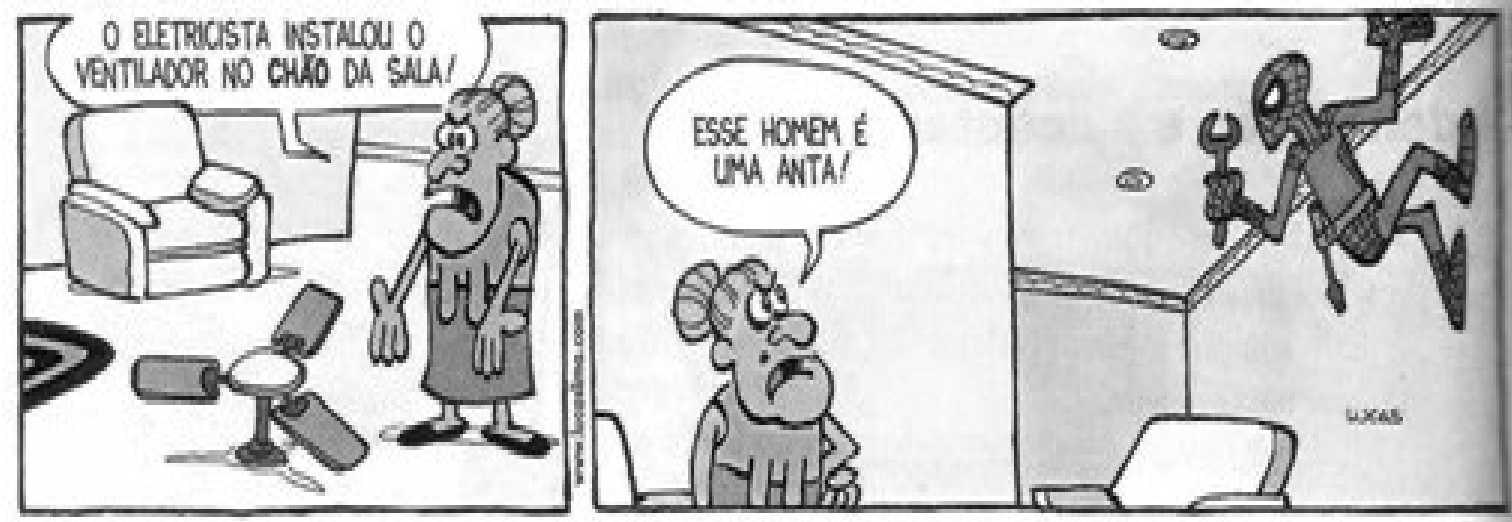

Whound imprish, lo/lohost

1. No li quadrinho, a personagem constata um erro absurdo na instalaço do ventilador Entretanto, considerando-se que o eletricista éc o homem do $2 \%$ quadrinho, a instalaçlo é um erro absurdo? Justifique sua resposta.

2. No $2 t$ quadrinho, a personagem chama o homem de anta.

a) Que sentido tem a palava anto nesse contexto?

b) Nesse caso a palsura onto fol empregada de modo denotativo ou conotativo?

\section{Figura 8: Fragmento de tira e atividades}

Fonte: Cereja e Magalhães. 


\subsection{PORTUGUÊS LINGUAGENS: VOLUME 1. 2010A, P. 118.}

No volume 1, unidade 2, encontramos alguns enfoques e exercícios a respeito de denotação e conotação. Na Figura 8, os autores trabalham o sentido das palavras em relação ao contexto. A atividade conduz o aluno a uma reflexão a respeito dos sentidos das palavras em cada contexto, o que desencadeia o humor na tira.

Como falamos no início deste item, os autores se preocuparam em destinar um capítulo aos estudos semânticos. O capítulo Introdução à Semântica é iniciado com uma atividade reflexiva sobre a propaganda de uma campanha sobre exploração sexual infantil (Figura 9). Os enunciados trazem a palavra pena empregada propositalmente com dois sentidos que ajudam a compor a propaganda.

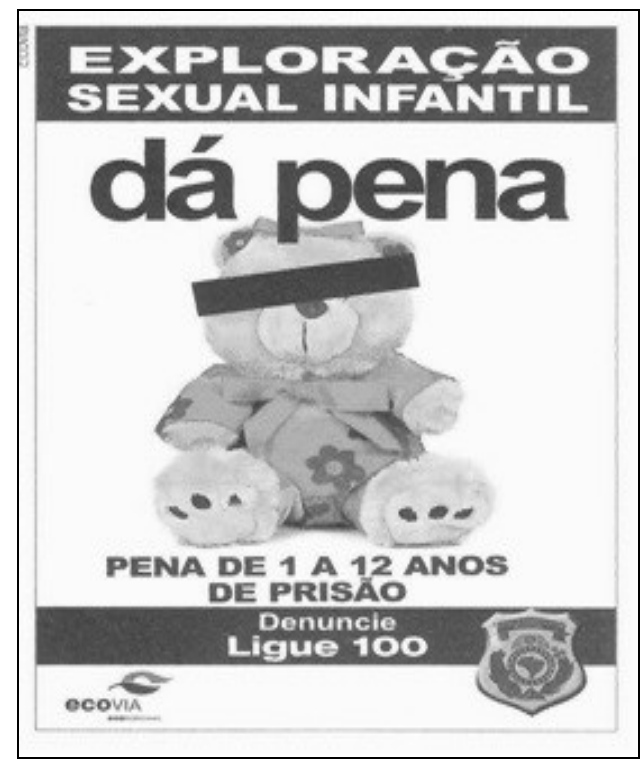

\section{Figura 9: Fragmento de texto de propaganda}

Fonte: Cereja e Magalhães. Português linguagens: volume 1. 2010a, p. 136

As atividades desenvolvidas, a partir da Figura 9, pelos autores da coleção Português Linguagens, são relevantes, pois exploram os vários sentidos que podem ser atribuídos às palavras empregadas no texto. Assim sendo, trabalham com a ambiguidade intencional ocasionada pela polissemia da palavra pena. Posteriormente, Cereja e Magalhães propõem alguns textos e atividades, reiterando o propósito de o aluno verificar os vários sentidos das palavras em textos diversos. Após esse contexto, os autores apresentam a definição de Semântica: "Semântica é a parte da gramática que estuda os aspectos relacionados ao sentido de palavras e enunciados”. E acrescentam: "alguns dos aspectos tratados pela Semântica são: sinonímia, antonímia, campo semântico, hiponímia, hiperonímia e polissemia” (CEREJA e MAGALHÃES, 2010a, p. 138). 


\section{Compare estes dois enunciados:}

- Rubens e Márcia estão se separando, você sabia?

- Rubens está se separando de Márcia, você sabia?

Em ambos os enunciados a separação do casal é inevitável. Porém os dois apresentam diferença de sentido.

a) Qual é essa diferença?

b) Levante hipóteses: A que se deve essa alteração de sentido?

\section{Figura 10: Fragmento de atividade.}

Fonte: Cereja e Magalhães. Português linguagens: volume 1. 2010a, p. 141

A atividade 5 (Figura 10) é pertinente, pois discute o emprego das palavras em uma mesma situação e os sentidos proporcionados pelas palavras. A partir da forma como foram construídos os enunciados, é possível observar uma diferença de sentido, pois, no segundo enunciado, entendemos que Rubens é quem está se separando de Márcia, quando no primeiro, entende-se, pelo emprego das palavras, que ambos estão em comum acordo com a separação. Os autores poderiam ter trabalhado a pressuposição nas sentenças, assim como argumentam Ilari e Geraldi (2006, p. 61): "Uma oração pressupõe outra quando a verdade e a falsidade da primeira tornam inescapável a verdade da segunda”.

Verificamos que os autores, no capítulo Introdução à Semântica, contextualizam e fazem uma introdução aos estudos semânticos através de textos, propagandas, fragmentos de textos e de exercícios. Em seguida, trazem mais exemplos e definições sobre várias vertentes de estudos semânticos; atividades envolvendo tiras, peças publicitárias e apontam, ainda, a relação de alguns desses elementos com a construção do texto, a exemplo, a ambiguidade.

Ao observar o sumário do volume 2, não encontramos nenhum capítulo específico destinado aos estudos semânticos, porém, como ocorreu nos demais volumes desta coleção, temos o campo Semântica e discurso, o qual pontua atividades voltadas para os significados. Dessa forma, não há apagamento do estudo dos sentidos.

A tira da Figura 11 apresenta, em sua essência, os sentidos proporcionados pelos artigos definidos e indefinidos. Novamente temos a pressuposição de determinadas sentenças nos enunciados da tira. As demais questões exploram os sentidos que podem ser conferidos aos artigos. Notamos que, no volume 2 da coleção Português Linguagens, assim como nos demais volumes, há uma integração de estudos relacionados ao sentido, à sintaxe e ao texto, o que é muito positivo, considerando-se que não há como se estudar semântica desassociada das demais partes da gramática. Ela envolve o léxico, a estrutura, o estilo, a entonação. 


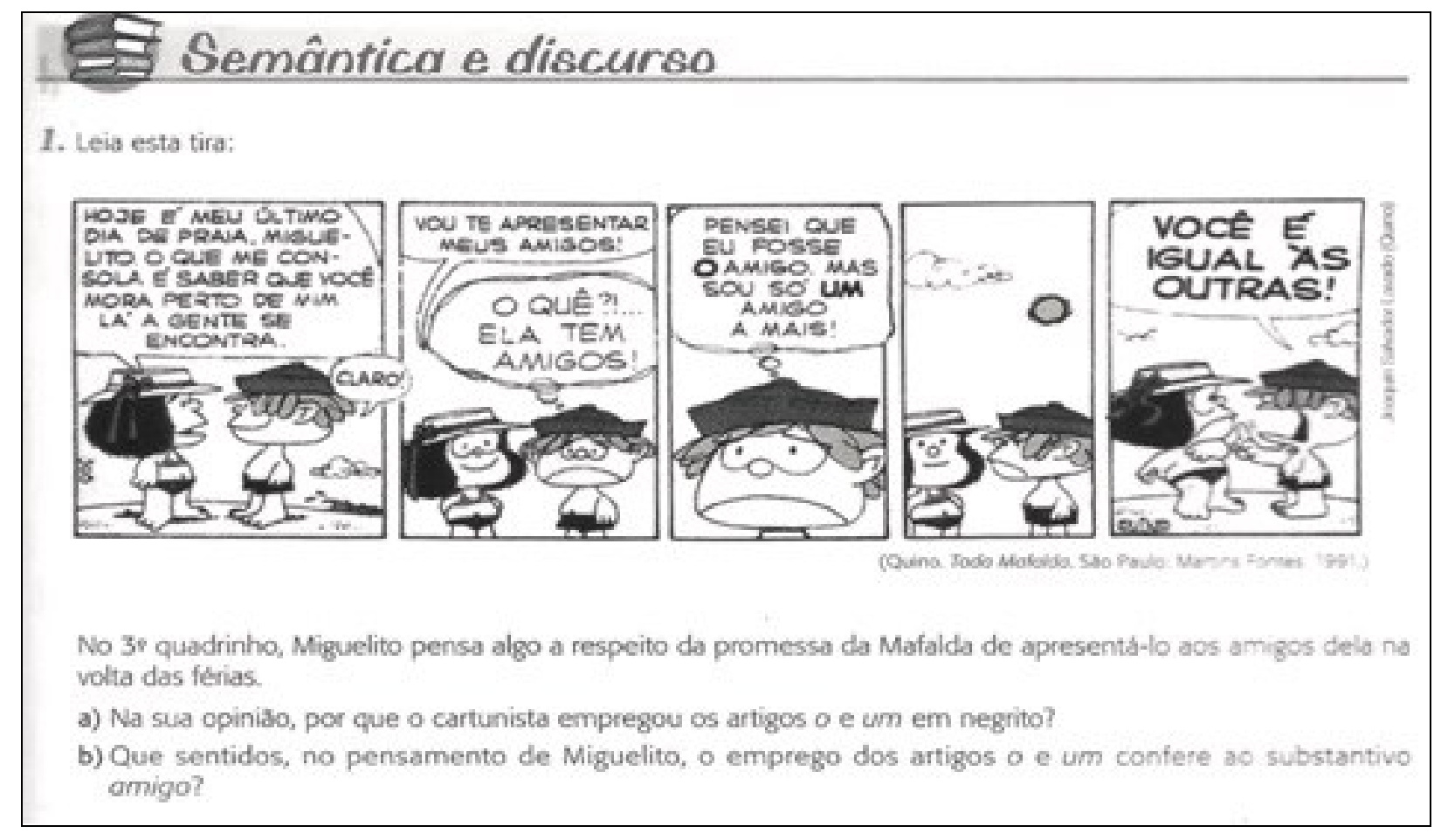

\section{Figura 11: Fragmento de tira e atividade}

Fonte: Cereja e Magalhães. Português linguagens: volume 2. 2010b, p. 71.

Passamos agora para o volume 3 da Coleção Português Linguagens. O primeiro campo sobre Semântica e discurso é destinado ao estudo do período composto por subordinação, iniciando com as orações subordinadas substantivas. Contudo, verificamos nas atividades, pouquíssimas abordagens semânticas, com mais ênfase na parte estrutural, sintaxe. No campo Semântica e discurso, capítulo 7, unidade 1, temos atividades sobre um anúncio da Revista Terra da Gente (Figura 12).

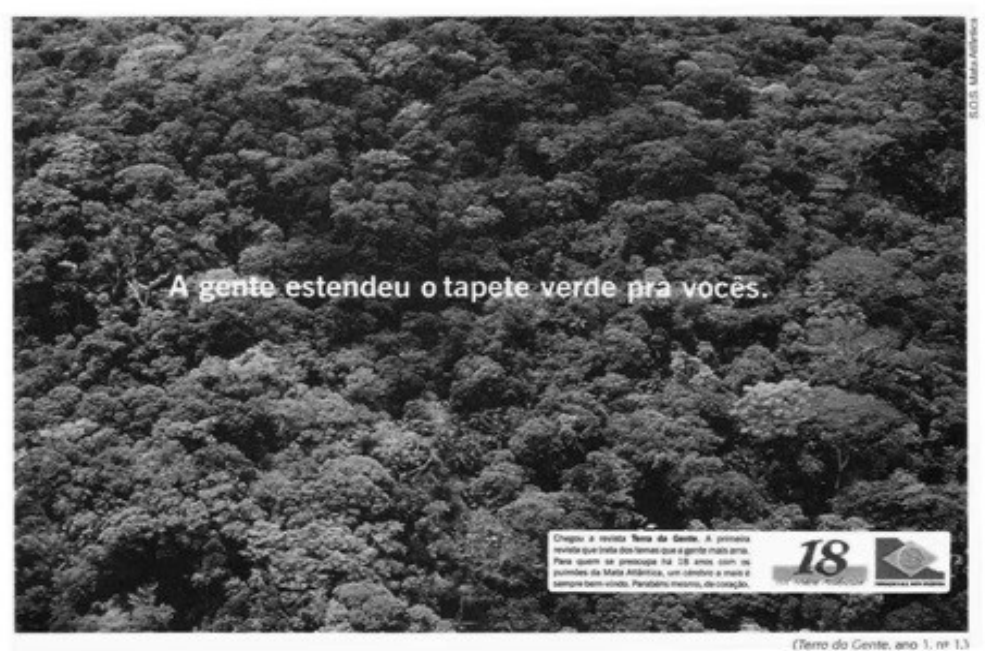

\section{Figura 12: Fragmento de publicidade}

Fonte: Cereja e Magalhães. Português linguagens: volume 3. 2010c, p. 88 
Na Figura 12, temos a oração "A gente estendeu o tapete verde pra vocês" em que os autores fazem uma abordagem do sentido da expressão tapete verde. Na parte inferior do anúncio, abordam também a expressão "um cérebro a mais". Pela linguagem verbal e não verbal, os autores poderiam ter explorado o sentido da oração "A gente estendeu o tapete verde pra vocês" levando os alunos a uma reflexão: o que leva a oração a ter tal sentido? sem o contexto da linguagem não verbal qual seria o significado da oração?

Contudo, observamos na coleção Português Linguagens, que os autores William R. Cereja e Thereza C. Magalhães se preocuparam em dedicar um capítulo aos estudos semânticos, além de abordarem, nos três volumes, o campo Semântica e discurso que contempla direta e, também, indiretamente os estudos a respeito de semântica, conduzindo os alunos a uma reflexão sobre os estudos voltados para os significados.

\section{CONSIDERAÇÕES FINAIS}

Como propusemos, fizemos um estudo em alguns livros didáticos destinados ao ensino médio da Rede Pública de Educação, para verificar como ou se a Semântica vem sendo trabalhada. Gostaríamos de deixar claro que nosso objetivo não foi fazer uma crítica aos autores e aos livros didáticos, pois não fizemos um estudo contemplando todos os quesitos inseridos no componente curricular, mas sim, nos restringimos a um olhar semântico.

Com a análise desenvolvida, percebemos que, para alguns autores, a Semântica não parece ser uma preocupação, todavia, utilizam atividades reflexivas e indiretas para trabalhar essa temática. Vimos certa barreira em apresentar determinadas abordagens, no entanto, alguns autores, cientes da importância dos estudos do significado, dedicaram um espaço para os estudos semânticos.

Assim sendo, através dos apontamentos realizados em nossa análise, podemos dizer que os estudos semânticos estão sendo inseridos nos materiais didáticos. Todavia, há um desequilíbrio na dosagem desse conteúdo. Ressaltamos que o livro didático não é a única ferramenta que o professor utiliza em sala de aula, ele é um recurso pedagógico e o professor deve saber utilizá-lo e fazer um paralelo com outros recursos e materiais.

Por fim, é relevante dizer que os estudos semânticos estão sendo inseridos nos materiais didáticos, mas ainda não podemos considerar como uma inserção ideal. Sugerimos dois pontos para ampliar a gama de estudos semânticos: primeiro, a apropriação do conhecimento das correntes teóricas da Semântica; segundo, ultrapassar o ambiente acadêmico para propagar os estudos semânticos. 


\section{REFERÊNCIAS}

BIERWISCH, Manfred. Semântica. In: Novos horizontes em Linguística; organizador John Lyons. São Paulo: Cultrix, EDUSP, 1976.

BORBA, Francisco da Silva. Introdução aos estudos linguísticos. Campinas, SP: Pontes Editores, $16^{\circ}$ ed., 2008.

CEGALLA, Domingos Paschoal. Novíssima gramática da língua portuguesa. Domingos Paschoal Cegalla. $46^{\circ}$ ed. São Paulo: Companhia Editora Nacional, 2005.

CANÇADO, Márcia. Manual de Semântica: noções básicas e exercícios. Belo Horizonte: Editora UFMG, 2005.

CEREJA, William Roberto; MAGALHÃES, Thereza Cochar. Gramática reflexiva: texto, Semântica e interpretação. São Paulo: Atual, 1999.

. Português linguagens: v.1; $7^{\mathrm{a}}$ ed. reform. São Paulo: Saraiva, 2010a.

. Português linguagens: v. 2; $7^{\mathrm{a}}$ ed. reform. São Paulo: Saraiva, $2010 \mathrm{~b}$.

. Português linguagens: v. 3 ; $7^{\mathrm{a}}$ ed. reform. São Paulo: Saraiva, 2010c.

FERRAREZI JR, Celso; BASSO, Renato (orgs.). Semântica, Semânticas: uma introdução/ organizadores Celso Ferrarezi Junior e Renato Basso. São Paulo: Contexto, 2013.

FERREIRA, Aurélio Buarque de Holanda. Mini Aurélio: o dicionário da língua. $8^{\mathrm{a}}$ ed. Curitiba: Positivo, 2010.

ILARI, Rodolfo; GERALDI, João Wanderley. Semântica. 11ª ed. São Paulo: Ática, 2006. $\overline{2011}$.

Introdução ao estudo do léxico: brincando com as palavras. $5^{\text {a }}$ ed. São Paulo: Contexto,

LYONS, John (org.). Novos horizontes em Linguística. São Paulo: Cultrix, EDUSP, 1976.

MAIA, João Domingues. Português. V. único; 2a ed. São Paulo: Ática, 2005.

MÜLLER, Ana Lúcia de Paula; VIOTTI, Evani de Carvalho. Semântica Formal. In: FIORIN, José Luis (org.). Introdução à Linguística II: princípios de análise. $4^{\mathrm{a}}$ ed., $2^{\mathrm{a}}$ reimpressão. São Paulo: Contexto, 2008.

FARACO, Carlos Emílio; MOURA, Carlos Emílio; MARUXO, Hamilton. Língua Portuguesa: linguagens e interação. v.1. São Paulo: Ática, 2010a.

. Língua Portuguesa: linguagens. v. 2. São Paulo: Ática, 2010b.

. Língua portuguesa: linguagens e interação. v.3. São Paulo: Ática, 2010c.

SACCONI, Luiz Antonio. Nossa gramática completa. $31^{\mathrm{a}}$ ed. rev. São Paulo: Nova Geração, 2011.

SAUSSURE, Ferdinand de. Curso de Linguística geral. 27ª ed. São Paulo: Cultrix, 2006. 